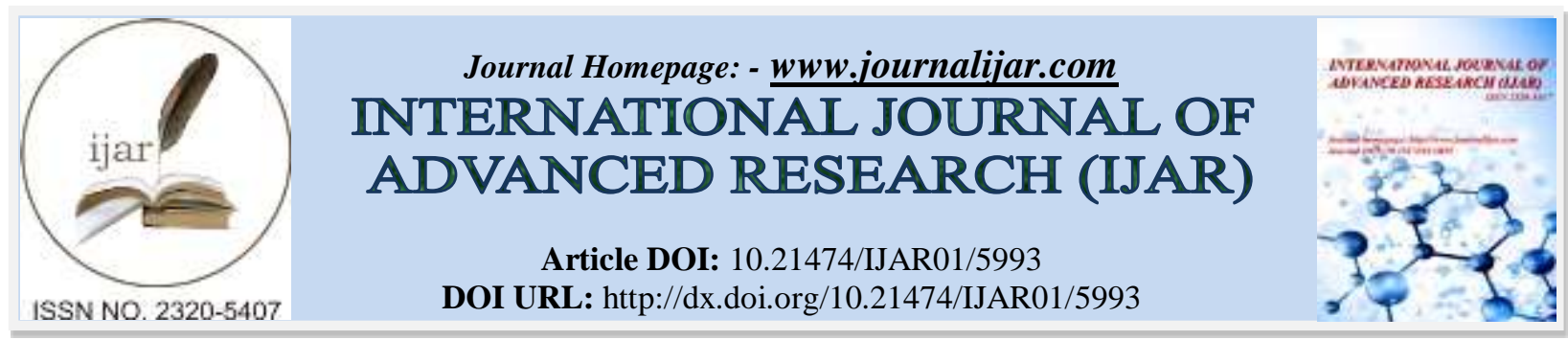

RESEARCH ARTICLE

\title{
FUNCTIONAL DISABILITY AMONG PATIENTS WITH DEPRESSIVE DISORDER ASSOCIATED WITH COGNITIVE IMPAIRMENT AT KING ABDULAZIZ HOSPITAL- MAKKAH.
}

\author{
Moayyad Suliman Alsalem. \\ Department of Psychiatry, King AbdulAziz Hospital, Makkah, Saudi Arabia.
}

\section{Manuscript Info}

Manuscript History

Received: 07 October 2017

Final Accepted: 09 November 2017

Published: December 2017

Key words:-

Depressive disorder; Cognitive dysfunction; MDI; Functional disability.

\section{Abstract}

Background: Depression is a mood disorder that results in negative thoughts, disruption of thinking, sleep and appetite. A depressive disorder is occurring with cognitive impairment, and depressed patients tend to suffer decreased performance. The study aims to assess the incidence of depressive disorder and its association with functional disability and cognitive impairment. Determine the impact of a depressive disorder associated with cognitive impairment on functional disability among patients.

Methods: This study is descriptive cross-sectional which included 150 patients from Makkah and treated at King Abdulaziz Hospital.

Results: The mean age of patients in this study was $36.12 \pm 10.93$, the male and female were in equal ratio $1: 1$. The most prevalent degree of depression was severe depression $31.3 \%$, followed by mild depression $29.3 \%$, no depression $20.7 \%$ and finally moderate depression $18.7 \%$. Age, sex, education, and occupation significantly affected the severity of depression. There was a positive correlation between cognitive dysfunction and functional disability $(\mathrm{P}$-value $=0.001, \mathrm{r}=0.433)$, with a strong positive correlation to family life $(\mathrm{P}$-value $=0.001, \mathrm{r}=0.71)$.

Conclusion: Severe depression was the most prevalent degree of depression, and it was significantly associated with cognitive impairment, functional disability and decreased work productivity. The increase in the severity of depression was related to the greater cognitive impairment and increase in functional disability as well as work productivity. Functional disability increases with increasing in cognition dysfunction.

Copy Right, IJAR, 2017,. All rights reserved.

\section{Introduction:-}

Depressive disorder is co-occurring with cognitive impairment and has further effect or adverse outcomes for physical health, functional status, and mortality (Potter, et al. 2007). Depression is a disorder of mood that produces sad feelings, negative thoughts, and disruptions of sleep, appetite, thinking, and energy level (American Psychiatric Association, 2000). Most research on neurocognitive deficits in depression has found that depressed individuals tend to have decreased performance relative to non-depressed control participants on a number of neuropsychological measures. In addition, experimental studies have found that depressed individuals have more ability to be affected by executive function (Boone, et al., 1995) and memory (Austin, et al., 1999). Increasing severity of depression and specific symptoms appeared to have a strong association to deficits in executive functions and information 
processing speed (Austin, et al., 1999). Hence, it appeared that the deficits in executive functions, associated with a number of mediated cognitive processes, such as selective attention, response inhibition, planning, and performance monitoring, are related with functional disability in depression (Kiosses, et al., 2001). Depressive Disorder is considered to be the second leading medical cause of burden globally, with highest estimates of disability in people of working age. In Canada, the annual prevalence of Depressive Disorder is 3\% to 4\% overall, and 79\% of people with Depressive Disorder report some interference with work functioning, either decreased work productivity or absenteeism. In addition to work impairment, the psychosocial impact of Depressive Disorder often affects a person's level of functioning in family and social relationships (Lam, et al., 2014).

Meanwhile, cognitive dysfunction refers to deficits in attention, verbal and nonverbal learning, short-term and working memory, visual and auditory processing, problem solving, processing speed, and motor functioning. Cognitive dysfunction may be a primary mediator of functional impairment in Depressive Disorder (McIntyre, et al., 2013).

The prevalence of Depressive Disorder is influenced by factors like hospitalization, where it is estimated at nearly $50 \%$ for major and minor depression (Koenig et al., 2004). The prevalence rate of depression in nursing homes is approximately $25 \%$ (Gerety, et al., (1994). It's was found that depression is nearly twice as prevalent in women as in men. On the other hand, deficits in cognitive performance occur most consistently among older individuals with a first onset of depression in late life, though some evidence suggests that memory deficits may be more pronounced among older individuals with early-onset depression (Rapp, et al., 2005)

Given that depression is highly prevalent in mild cognitive impairment, it is important to detect and effectively treat depression because the comorbidity of depression and cognitive impairment is associated with greater cognitive and functional decline and higher rates of institutionalization. Screening of depression and cognitive impairment will help characterize the presence and severity of these conditions, but limitations in screening approaches may necessitate comprehensive assessment in complex cases where differential diagnosis is important to treatment planning (Potter, et al. 2007).

Although cognitive impairment and depressive symptoms are associated with functional decline, it is not understood how these risk factors act together to affect the risk of functional decline. As of this writing, studies concerning the functional disability among patients with depressive disorder associated with cognitive impairment in Saudi Arabia is very limited, hence, doing this study is not only relevant but also a necessity.Confidently, this research will increase knowledge and awareness of depressive disorder as a cause of cognitive impairment and its relation with functional disability in Saudi Arabia. We also intend to integrate this current research and perhaps develop strategies for the assessment and treatment of depression in the context of cognitive impairment. The given results will be needed to guide clinical decision and improve the outcomes.

Kim et al. (2016) investigated functional disability, productivity and quality of life in MDD outpatients in South Korea, and the associations of these with depressive symptoms, perceived cognitive dysfunction and other factors. A total of 312 outpatients who started antidepressant monotherapy underwent a single study interview. Results showed that greater functional disability and impairment in daily activities were associated with more severe depression and greater perceived cognitive dysfunction. Irrespective of depression severity, patients with more severe perceived cognitive dysfunction reported worse work-related productivity outcomes (higher presenteeism and greater overall work productivity loss). PERFORM-K confirms the impact of MDD on functional status and well-being in South Korean patients and highlights the importance of recognizing cognitive dysfunction in clinical practice.

Sheehan et al. (1996) studied the correlation between severity of depression and cognitive impairment among the depressed students of Cairo University Hospital. Fifty patients in Kasr El Aini Hospital with the diagnosis of Major Depressive Disorder according to the DSM-IV criteria were recruited from the psychiatric outpatient clinic of Cairo University Student Hospital, with no sexual preference. Fifty control participants of similar age, sex, and educational background were recruited as volunteers. Psychometric procedures used were: Beck Depression Inventory for severity of depression, selected subtests of Wechsler Adult Intelligence Scale (WAIS), and Wechsler Memory Scale-Revised (WMS-R). Results showed that medical and paramedical students recruited from six faculties constituted $40 \%$ of the entire sample. Forty percent of the cases were diagnosed with moderate depression, whereas $60 \%$ were diagnosed with severe depression. All the scores of the subtests of WAIS and WMS-R used were higher in the control group. The scores of the Beck Depression Inventory were correlated positively with the digit symbol 
and digit span subtests of WAIS and to figural memory and visual memory span subtests of WMS-R. They concluded that depressed undergraduate university students had more cognitive deficits than those with no depression. The severity of depression was correlated positively with some of these cognitive deficits.

Rock et al. (2014) conducted a meta-analysis to determine if cognitive impairment should be considered a core feature of depression that may be a valuable target for treatment using a single neuropsychological test battery, the Cambridge Neuropsychological Test Automated Battery (CANTAB) in patients with depression during symptomatic and remitted states. The study revealed that both low mood and cognitive impairment are associated with poor psychosocial functioning, which leads to a conclusion that cognitive impairment represents a core feature of depression that cannot be considered an epiphenomenon that is entirely secondary to symptoms of low mood and that may be a valuable target for future interventions.

Mehta et al. (2002) determined the relative contributions of cognitive impairment and depressive symptoms on the decline in activity of daily living (ADL) function over two years in an older cohort. Five thousand six hundred ninety-seven participated in the study (mean age 77, 64\% women, 86\% white) followed from 1993 to 1995 . Results concluded cognitive impairment and depressive symptoms are risk factors for the decline in activity of participants with no ADL dependence at baseline, while only cognitive impairment is a risk factor for the decline in activity of participants with dependence in ADL at baseline.

From the presented studies, it is evident that depression's disability is associated with cognitive impairment on patient's cognition and functional life. However, studies that assessed the effect of Depression's disability related to cognitive impairment in Saudi Arabia is very limited. Also, to the best of our knowledge as of this writing, no study similar is yet carried out in Makkah City. Hence, this is proposal was conceptualized.

\section{Materials and Methods:-}

\section{Study design:-}

This study will utilize descriptive cross-sectional research design. This is the most suitable design to describe the incidence of functional disability among patients with a depressive disorder associated with cognitive impairment across patients at King Abdulaziz Hospital and determine its statistical correlation.

\section{Study area/setting:-}

The study will be carried out at King Abdulaziz Hospital, Makkah City, Saudi Arabia.

\section{Study population: -}

All patients $(n=150)$ in Makkah City who attended the psychiatry outpatient department at King Abdulaziz Hospital with depressive symptom will be eligible for inclusion in the study.

\section{Sample size and sampling:-}

Patients (Males "n=75 "and Females "75") treated at King Abdulaziz Hospital in Makkah will be invited to participate in the study by filling the study questionnaire by themselves or assisted by their partner or caregivers.

\section{Inclusion criteria:-}

After taking the approval from the hospital ethical committee, patients with the depressive disorder will be eligible to be included in the study. Consent will be taken from the parents or legal guardian of children participants. All demographic data and investigation findings will be noted.

\section{Exclusion criteria:-}

Patients are not fulfilling inclusion criteria, and cases with incomplete data will be excluded from the study.

\section{Data collection instrument:-}

A researcher -administered questionnaire will be used in this study consisting of two sections:

Section one: - Personal information.

Section two: - Background information that consists of two parts: 


\section{Part 1:-}

Consist of 10 items for depression disorder assessment using Major Depression Inventory (MDI) questionnaire. Responses will include all of the time, most of the time, slightly more than half of the time, slightly less than half of the time, some of the time, and no time with a scale of 5, 4, 3, 2, 1, 0 respectively.

\section{Part 2:-}

In this part, Cognitive Dysfunction, Functional Disability and Work Productivity and Activity Impairment will be assessed.

Assessment of Cognitive dysfunction by using the Perceived Deficits Questionnaire for Depression (PDQ-D). A 20item instrument assesses four subscales: attention/concentration, retrospective memory, prospective memory and planning/organization.

Regarding Functional Disability, The Sheehan Disability Scale (SDS) will be used. It is a brief, 5-item self-report tool that assesses functional impairment over the previous seven days in three domains: work/school, social life, and family life.

For assessment of work productivity, The Work Productivity and Activity Impairment, Specific Health Problems Questionnaire (WPAI: SHP) will be used to measure impairment in productivity related to work and regular daily activities.

\section{Results:-}

The present study included 150 participants, the mean age was $36.12 \pm 10.93$ years; there were $46(30.7 \%)$ their ages less than 30 years, $82(54.7 \%)$ their ages ranged from $30-49$ and $22(14.7 \%)$ their ages $\geq 50$ years. The number of females and males in this study was equal, and each group represented $50 \%$ of the sample size. Most of the participants were in pre-college education 58 (38.7\%), followed by participants with degree 40 (26.7\%), those with diploma $35(23.3 \%)$, those who had masters $10(6.7 \%)$ and finally illiterate and those who had Ph.D. represented 4 $(2.7 \%)$ and $3(2 \%)$ respectively. There were 59 (39.3\%) self-employed, 42 (28\%) employed, 26 (17.3\%) unemployed, $20(13.3 \%)$ students and $3(3 \%)$ retired.

MDI was used for assessment of depression disorders, no depression or doubtful depression scored from 0-20, mild depression 21-25, moderate depression 26-30 and severe depression from 31-50, the prevalence of different depression degrees is shown in (figure 1). Severe depression was the most prevalent among participants $31.3 \%$, followed by mild depression $29.3 \%$, no or doubtful depression $20.7 \%$ and finally moderate depression $18.7 \%$. The correlation between severity of depression and demographics was investigated. Age, sex, education, and occupations were factors that significantly affected the severity of depression (table 1). Regarding age, the age group of 30-49 years was the most group to experience severe depression $(68.1 \%)$. Females were more prone to experience severe depression (63.8\%). Also, more participants with a university and higher education experienced severe depression $(61.7 \%)$, severe depression was more common in employed and self-employed participants $(68.1 \%)$.

Figure 1:- Prevalence of Depression Degrees among the participants.

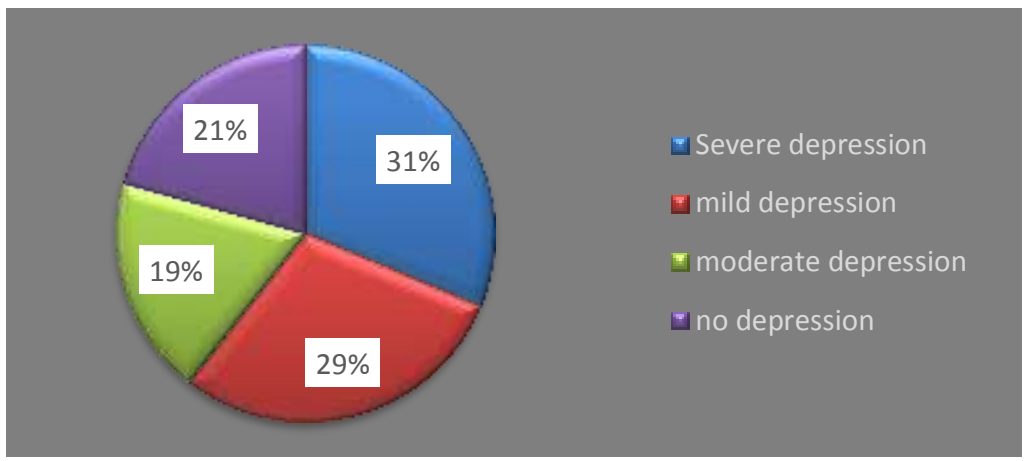


Table1:- The correlation between depression and demographics.

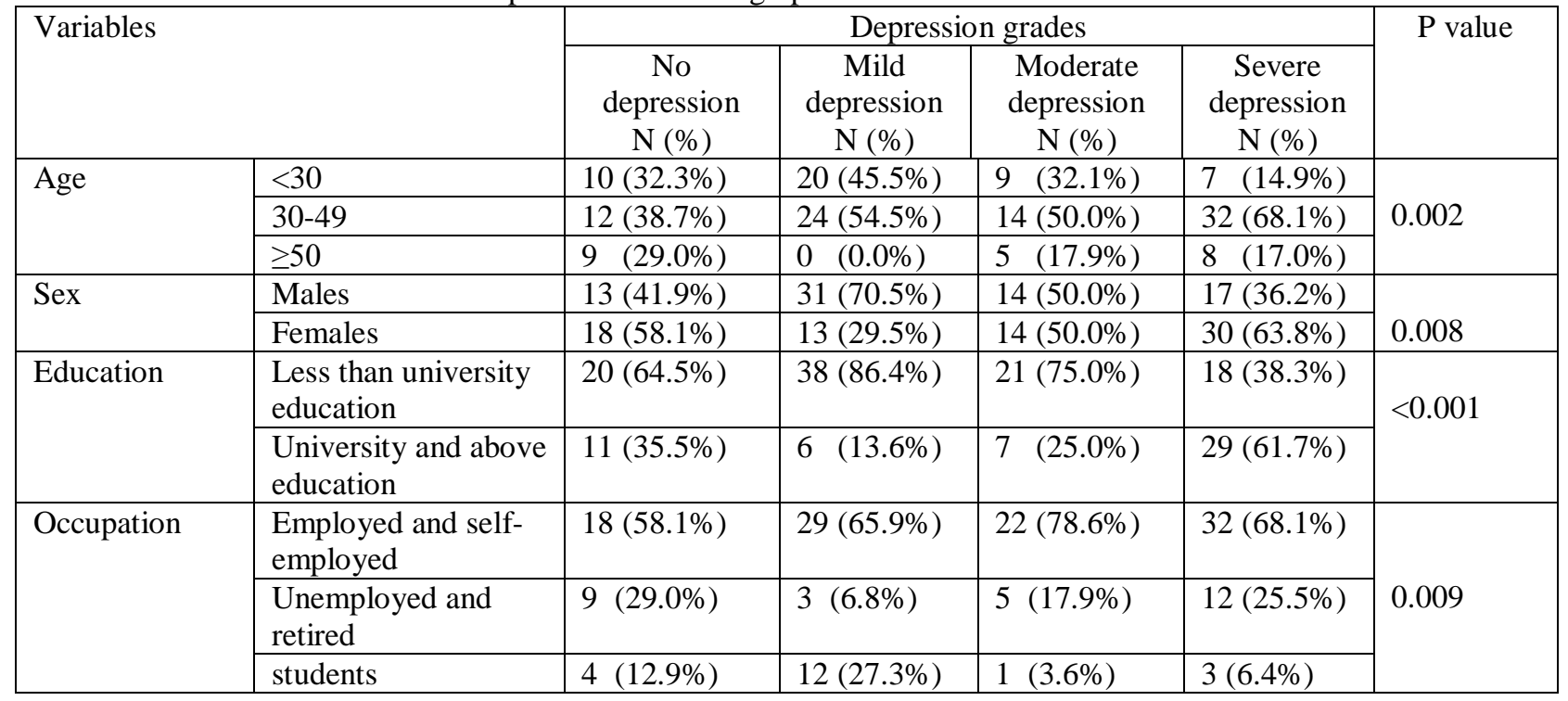

The mean score of cognitive dysfunction was $37.77 \pm 10.24$, cognitive dysfunction assessment involved assessment of the mean score of 4 subscales; attention/ concentration (mean $\pm \mathrm{SD}=9.6 \pm 2.9$ ), retrospective memory (mean \pm $\mathrm{SD}=9.7 \pm 2.8$ ), prospective memory (mean $\pm \mathrm{SD}=9.6 \pm 3$ ) and planning organization subscale (mean $\pm \mathrm{SD}=8.8 \pm 2.6$ ). The four subscales of cognitive dysfunction were significantly affected by depression degrees, (table 2). Severe depression was correlated to the highest mean of scores of the four subscales and the total mean of PDQ.

Table2: - Correlation between cognitive dysfunction subscales and depression.

\begin{tabular}{|c|c|c|c|}
\hline Cognition score & Level of depression & Mean \pm SD & $P$ value \\
\hline \multirow{4}{*}{$\begin{array}{l}\text { Attention/Concentration } \\
\text { Subscale }\end{array}$} & No or doubtful depression & $6.87 \pm 2.47$ & \multirow{4}{*}{$<0.001$} \\
\hline & Mild depression & $9.31 \pm 2.50$ & \\
\hline & Moderate depression & $9.67 \pm 2.35$ & \\
\hline & Severe depression & $11.82 \pm 2.08$ & \\
\hline \multirow[t]{4}{*}{ Retrospective Memory Subscale } & No or doubtful depression & $7.00 \pm 2.38$ & \multirow{4}{*}{$<0.001$} \\
\hline & Mild depression & $9.50 \pm 2.27$ & \\
\hline & Moderate depression & $8.92 \pm 2.35$ & \\
\hline & Severe depression & $12.14 \pm 1.81$ & \\
\hline \multirow[t]{4}{*}{ Prospective Memory Subscale } & No or doubtful depression & $6.87 \pm 2.87$ & \multirow{4}{*}{$<0.001$} \\
\hline & Mild depression & $9.72 \pm 2.72$ & \\
\hline & Moderate depression & $9.10 \pm 2.14$ & \\
\hline & Severe depression & $11.80 \pm 2.26$ & \\
\hline \multirow[t]{4}{*}{ Planning/Organization Subscale } & No or doubtful depression & $5.77 \pm 2.34$ & \multirow{4}{*}{$<0.001$} \\
\hline & Mild depression & $9.13 \pm 1.86$ & \\
\hline & Moderate depression & $8.67 \pm 1.78$ & \\
\hline & Severe depression & $10.68 \pm 2.05$ & \\
\hline \multirow[t]{4}{*}{ PDQ Total Score: } & No or doubtful depression & $26.51 \pm 8.87$ & \multirow{4}{*}{$<0.001$} \\
\hline & Mild depression & $37.68 \pm 7.54$ & \\
\hline & Moderate depression & $36.39 \pm 6.52$ & \\
\hline & Severe depression & $46.46 \pm 6.71$ & \\
\hline
\end{tabular}


Assessment of functional disability involved assessment of the function in work/school, social life, family life, days unproductive and day lost. The mean scores of these five scales are shown in figure (2).

Figure 2:- Mean Score of Function Disability.

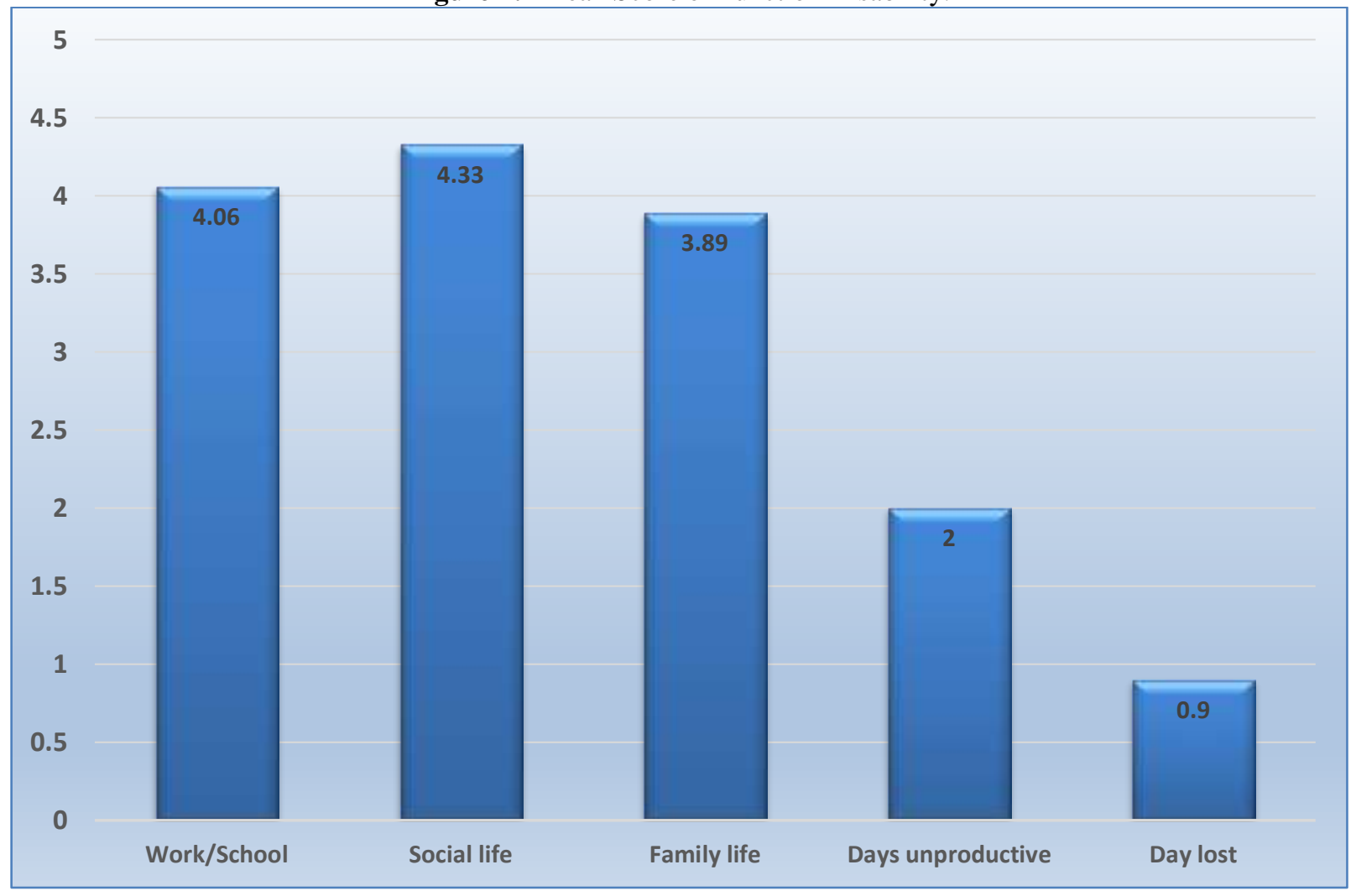

There was a significant correlation between the mean score of functional disability and depression grades (Pvalue $=0.001$ ), the mean score of functional disability was increased by increasing severity of depression; in case of no depression, the functional disability mean score $=7.25 \pm 2.9$, in case of mild depression the mean score of functional disability $=12.15 \pm 2.7$, in case of moderate and severe depression the mean functional disability score $=$ $11.39 \pm 3.5$ and $14.48 \pm 5.8$ respectively.

Regarding the correlation between cognitive impairment which was assessed by PDQ-D and functional disability, there was a significant positive correlation ( $\mathrm{P}$-value $=0.001, \mathrm{r}=0.433$ ), where the functional disability increase by increasing the cognitive impairment. Regarding the three aspects of the functional disability; work/school, social life, and family life, also positive correlations were found, where the correlation between work/school and cognitive impairment was moderately positive $(\mathrm{P}$-value $=0.001, \mathrm{r}=0.570$ ), while the correlation between social life and cognitive impairment was weakly positive $(\mathrm{P}$-value $=0.001, \mathrm{r}=0.420)$ and the correlation between family life and cognitive impairment was strongly positive ( $\mathrm{P}$-value $=0.001, \mathrm{r}=0.710$ ). Assessment of work productivity involves assessment of 4 items; Absenteeism, Presenteeism, Work productivity loss and Activity impairment, the mean scores of these items were $20.6 \pm 18,48.41 \pm 21.28,1112 \pm 1348$ and $46.86 \pm 18.61$ respectively. The previous four items were significantly differed by depression grades (table 3 ). The mean score of absenteeism, presenteeism, work productivity and activity impairment were increased by increasing the severity of depression. The mean score of absenteeism in case of no depression was $12.11 \pm 22.69$, by increasing the degree of depression and in case of severe depression, the mean score of absenteeism increased $29.68 \pm 18.76$. The same was found in case of presenteeism, where the mean score of presenteeism was lower $(23.68 \pm 12.11)$ in those with no depression than the mean score $(68.12 \pm 22.49)$ in those with severe depression. The work productivity loss means score increased significantly with increasing depression degree, in the absence of depression the mean score of work productivity loss was $198.15 \pm 254.88$, while in severe depression the mean score increased to $2227 \pm 1888.7$. In case of severe depression, the mean score of activity impairment increased $(61.48 \pm 16.6)$ than in case of no depression $(25.8 \pm 13.3)$. 
Table 3:- The correlation between work productivity and depression grades.

\begin{tabular}{|c|c|c|c|}
\hline Work productivity & Depression grades & Mean (SD) & $\mathrm{P}$ value \\
\hline \multirow[t]{4}{*}{ Absenteeism*1 } & No or doubtful depression & $12.11(22.69)$ & \multirow[t]{4}{*}{$<0.001$} \\
\hline & Mild depression & $22.78(14.64)$ & \\
\hline & Moderate depression & $11.95(8.57)$ & \\
\hline & Severe depression & $29.26(18.76)$ & \\
\hline \multirow[t]{4}{*}{ Presenteeism $* 2$} & No or doubtful depression & $23.68(12.11)$ & \multirow[t]{4}{*}{$<0.001$} \\
\hline & Mild depression & $45.29(8.61)$ & \\
\hline & Moderate depression & $45.90(11.40)$ & \\
\hline & Severe depression & $68.12(22.49)$ & \\
\hline \multirow{4}{*}{$\begin{array}{l}\text { Work productivity } \\
\text { loss*3 }\end{array}$} & No or doubtful depression & $198.15(254.88)$ & \multirow[t]{4}{*}{$<0.001$} \\
\hline & Mild depression & $969.98(619.79)$ & \\
\hline & Moderate depression & $499.94(422.21)$ & \\
\hline & Severe depression & $2227(1888.71)$ & \\
\hline \multirow{4}{*}{$\begin{array}{l}\text { Activity } \\
\text { Impairment*4 }\end{array}$} & No or doubtful depression & $25.80(13.36)$ & \multirow[t]{4}{*}{$<0.001$} \\
\hline & Mild depression & $45.45(9.51)$ & \\
\hline & Moderate depression & $47.85(14.49)$ & \\
\hline & Severe depression & $61.48(16.67)$ & \\
\hline
\end{tabular}

\section{Discussion:-}

In the present study, the most dominant age group was the group with participants' age of 30-49 years, the number of males and females were equal. The most prevalent degree of depression was severe depression which represented $31.3 \%$, while moderate depression was the least to occur among participants. The present study revealed that age, sex, education, and occupation were significantly affected the severity of depression. The age group of those with 30-49 years was the most affected group with the different depression severity. However, this could be explained by the fact that the majority of participants were in this age group. Females were more prone to experience severe depression and suffering no depression, while males suffered more mild depression than females, the same percent of both genders experienced moderate depression, (P-value=0.008). No association between depression and gender was shown in Indian study (Villarreal, et al. 2015). Education was a factor that affected the degrees of depression $(\mathrm{P}$-value $=0.001)$, the participants with a university and above education experienced severe depression more than those of less education, while more participants with education less than university suffered no depression. The previous Indian study showed that there was an association between low educational achievement and depression. Employed and self-employed individuals experienced severe depression more than other groups; severe depression was less common in student group $(\mathrm{P}$-value $=0.009)$.

Several studies suggested that the risks of functional disability and cognitive impairment were increased by depression (Lebowitz, et al. 1997; Charney, et al. 2003). In the current study cognitive impairment was significantly affected by the severity of depression, where the total score of cognitive impairment increased with severity of depression (P-value=0.001). A previous study (Miskowiak, et al. 2012) suggested that severity of depression may be a predictor of cognitive impairment, while other previous studies (Fava, et al. 2009; kim, et al. 2016), reported a weak association between cognitive dysfunction and depression severity. In a study from Japan on participants aged 65 years and older, it was reported that cognitive impairment was more common in persons with depression (Hidaka, et al. 2012).

The four subscales of cognitive impairment were significantly affected by the severity of depression, and this reflects the increase in cognitive impairment of individuals. Cognitive impairment in retrospective memory domain was the highest among the other domains, the mean scores for individuals regarding memory (retrospective and prospective) increased by increasing the severity of depression (P-value=0.001), however (Kim, et al. 2016; Lam, et al. 2013) revealed that planning/organization and concentration/attention domains were predominances than memory domain. Regarding planning of individuals, the impairment of planning was increased with the severity of depression $(\mathrm{P}$-value $=0.001)$. 
A study in primary care showed that functional disability was high in patients with depression (McMahon, et al. 2012). In the current study, the mean score for the functional disability subscales did not exceed 4.3; the functional disability is significantly recognized at $\geq 5$ scores. However, by evaluating the correlation between depression degrees and functional disability, it was found that functional disability increased with increasing depression severity and it was significantly affected by depression degrees (P-value=0.001). In a Korean study by Kim, et al. 2016, they reported that greater functional disability was associated with severe depression.

Work productivity was represented by absenteeism, presenteeism, work productivity loss, and activity impairment. The current study showed that the four previous subscales were significantly increased by increasing severity of depression ( $\mathrm{p}$-value $=0.001$ for each subscale). Presenteeism was reported to be a greater problem than absenteeism in patients with depression; our results were in agreement with the results of previous studies (Stewart, et al. 2003; Sanderson, et al. 2006; Kim, et al. 2016). In case of severe depression, activity impairment increased greatly, this was by the European PERFORM study (Haro, et al. 2013) and the Korean study by Kim et al. 2016. Depression severity was significantly associated with work productivity loss $(\mathrm{P}$-value $=0.001$ ), and severe depression was correlated with the highest work productivity loss. However, this finding was in controversy with Kim et al. 2016 who reported that severity of depression was not significantly associated with any work outcome. In Canada, $79 \%$ of patients with depression reported either decrease in work productivity or absenteeism (Gilmour, et al. 2007).

WHO mental health surveys reported that depression was the most commonly reported mental illness in all three groups of countries led to productivity loss (4.9-6.2\%) (Alonso, et al. 2011).

The present study revealed that there was a positive correlation between functional disability and cognitive impairment $(\mathrm{P}$-value $=0.001, \mathrm{r}=0.433$ ), with a strong positive association between cognitive impairment and family life $(\mathrm{P}$-value $=0.001, \mathrm{r}=0.71)$, while moderate positive correlation was found between work/school and cognitive impairment ( $\mathrm{P}$-value $=0.001, \mathrm{r}=0.57)$, a weak positive association was found regarding social life and cognitive impairment $(\mathrm{P}$-value $=0.001, \mathrm{r}=0.42)$. This means that family life is the most affected by cognitive impairment, then work/school and then social life.

The positive association means that the increase in cognitive dysfunction leads to greater functional disability. This was in agreement with Korean study by Kim et al. 2016 which, showed that greater functional disability was associated with severe depression and cognitive dysfunction. Our study reported that higher level of functional disability was found in patients with severe perceived cognitive impairment.

\section{Conclusion:-}

From the present study, we could conclude that severe depression was the most prevalent among participants and mild depression was the less common. Several factors significantly influenced depression severity including age, gender, education, and occupation, the severity of depression significantly influenced cognitive dysfunction, where severe depression was associated with more cognitive dysfunction. Also, the severity of depression was associated with functional disability, where the functional disability increases with increasing depression severity. Work productivity was significantly related to depression severity; severe depression was associated with lower work productivity. The increase in the cognitive impairment which associated with the depression correlates directly with the increase in functional disability, especially in family life.

\section{Conflicts of Interest:-}

The author declares no conflict of interest. 


\section{References:-}

1. Alonso, J., Petukhova, M., Vilagut, G., Chatterji, S., Heeringa, S., Üstün, T. B., ... \& Bruffaerts, R. (2011). Days out of role due to common physical and mental conditions: results from the WHO World Mental Health surveys. Molecular psychiatry, 16(12), 1234-1246.

2. American Psychiatric Association. (2000) Diagnostic and Statistical Manual of Mental Disorders: DSM-IV-TR. 4th ed. Washington, DC: American Psychiatric Association. Text revision ed.

3. Austin, M.P., Mitchell, P., Wilhelm, K., et al. (1999) Cognitive Function in Depression: A Distinct Pattern of Frontal Impairment in Melancholia.Psychological Medicine. 29:73-85.

4. Boone, K., Lesser, B., Miller, B., et al. (1995) Cognitive Functioning In A Geriatric Depressed Population: Relationship Of Presence And Severity Of Depression ToNeuropsychological Scores. Neuropsychology, 9:390 $-398$.

5. Charney, D. S., Reynolds, C. F., Lewis, L., Lebowitz, B. D., Sunderland, T., Alexopoulos, G. S., ... \& Borson, S. (2003). Depression and Bipolar Support Alliance consensus statement on the unmet needs in diagnosis and treatment of mood disorders in late life. Archives of General Psychiatry, 60(7), 664-672.

6. Fava, M., Iosifescu, D. V., Pedrelli, P., \& Baer, L. (2009). Reliability and validity of the Massachusetts general hospital cognitive and physical functioning questionnaire. Psychotherapy and psychosomatics, 78(2), 91-97.

7. Gerety, M.B., Williams, J.W., Mulrow, C.D., et al. (1994) Performance OfCasefinding Tools For Depression In The Nursing Home: Influence Of Clinical And Functional Characteristics And Selection Of Optimal Threshold Scores. J American Geriatric Soc, 42:1103-1109.

8. Gilmour, H., \& Patten, S. B. (2007). Depression and work impairment. Health Reports, $18(1), 9$.

9. Haro, J. M., Chollet, J., Boulenger, J. P., Jönsson, B., Knapp, M., Rive, B., \& Saragoussi, D. (2013). Prospective Epidemiological Research on Functioning Outcomes Related to Major Depressive Disorder (perform): Design and Characteristics of First 1,000 Patients. Pharmacoepidemiology and Drug Safety, $22,507$.

10. Hidaka, S., Ikejima, C., Kodama, C., Nose, M., Yamashita, F., Sasaki, M., ... \& Kakuma, T. (2012). Prevalence of depression and depressive symptoms among older Japanese people: comorbidity of mild cognitive impairment and depression. International journal of geriatric psychiatry, 27(3), 271-279.

11. Kim, J. M., Chalem, Y., di Nicola, S., Hong, J. P., Won, S. H., \& Milea, D. (2016). A cross-sectional study of functional disabilities and perceived cognitive dysfunction in patients with major depressive disorder in South Korea: The PERFORM-K study. Psychiatry research, 239, 353-361.

12. Kiosses, D.N., Klimstra, S., Murphy, C., et al. (2001) Executive dysfunction and disability in elderly patients with major depression. American Journal of GeriatrPsychiatry. 9:369 -374.

13. Koenig, H.G., Blazer, D.G. (2004) Mood disorders. In: Blazer DJ, Steffens DC, Busse EW, eds. Textbook of Geriatric Psychiatry. Arlington, V.A.: American Psychiatric Publishing.

14. Lam, R., Kennedy, S., McIntyre, R., Atul Khullar, A. (2014) Cognitive Dysfunction in Major Depressive Disorder: Effects on Psychosocial Functioning and Implications for Treatment. The Canadian Journal of Psychiatry, 59(12):649-654.

15. Lam, R. W., Saragoussi, D., Danchenko, N., Rive, B., Lamy, F. X., \& Brevig, T. (2013). Psychometric validation of Perceived Deficits Questionnaire-Depression (PDQ-D) in patients with major depressive disorder (MDD). Value in Health, 16(7), A330.

16. Lebowitz, B. D., Pearson, J. L., Schneider, L. S., Reynolds, C. F., Alexopoulos, G. S., Bruce, M. L., ... \& Mossey, J. (1997). Diagnosis and treatment of depression in late life: consensus statement update. Jama, 278(14), 1186-1190.

17. Mehta, K., Yaffe, K., Covinsky, K. (2002) Cognitive Impairment, Depressive Symptoms, and Functional Decline in Older People. Journal of American Geriatr Society. 50(6): 1045-1050.

18. McMahon, E. M., Buszewicz, M., Griffin, M., Beecham, J., Bonin, E. M., Rost, F., ... \& King, M. (2012). Chronic and recurrent depression in primary care: socio-demographic features, morbidity, and costs. International journal of family medicine, 2012.

19. McIntyre, R.S., Cha, D.S., Soczynska, J.K., et al. (2013) Cognitive Deficits and Functional Outcomes in Major Depressive Disorder: Determinants, Substrates, And Treatment Interventions. Depress Anxiety, 30:515-527.

20. Miskowiak, K., Vinberg, M., Christensen, E. M., \& Kessing, L. V. (2012). Is there a difference in subjective experience of cognitive function in patients with unipolar disorder versus bipolar disorder?. Nordic journal of psychiatry, 66(6), 389-395.

21. Sanderson, K., \& Andrews, G. (2006). Common mental disorders in the workforce: recent findings from descriptive and social epidemiology. The Canadian Journal of Psychiatry, 51(2), 63-75.

22. Sheehan DV, Harnett-Sheehan K, Raj BA. The measurement of disability. International clinical psychopharmacology. 1996, 1, 11, 89-95. 
23. Stewart, W. F., Ricci, J. A., Chee, E., Hahn, S. R., \& Morganstein, D. (2003). Cost of lost productive work time among US workers with depression. Jama, 289(23), 3135-3144.

24. Rapp, M.A., Dahlman, K., Sano, M., et al. (2005) Neuropsychological differences between late-onset and recurrent geriatric major depression. American Journal of Psychiatry, 162:691- 698.

25. Rock, P.L., Roiser, J.P., Riedel, W.J., Blackwell A.D. (2014) Cognitive impairment in depression: a systematic review and meta-analysis. Psychological Medicine, 44(10):2029-40. doi: 10.1017/S0033291713002535.

26. Reilly, M. C., Zbrozek, A. S., \& Dukes, E. M. (1993). The validity and reproducibility of a work productivity and activity impairment instrument. Pharmacoeconomics, 4(5), 353-365.

27. Potter, G., and Steffens, D. (2007) Contribution of Depression to Cognitive Impairment and Dementia in Older Adults. The Neurologist, 13: 105-117

28. Villarreal, A. E., Grajales, S., Lopez, L., \& Britton, G. B. (2015). Cognitive impairment, depression, and cooccurrence of both among the elderly in Panama: differential associations with multimorbidity and functional limitations. BioMed research international, 2015. 